\title{
Development of Non-structural Flood Mitigation Policies and Measures for Pekan town, Malaysia
}

\author{
Mohammad Abdul Mohit, Gajikoh Mohamed Sellu \\ Kulliyyah (Faculty) of Architecture \& Environmental Design, \\ International Islamic University Malaysia, Kuala Lumpur, Malaysia \\ mamohit@iium.edu.my
}

\begin{abstract}
Floods bring miseries to the life of thousands of Malaysians every year. Pekan town, located on the banks of the Pahang River, regularly suffers both economic damages and physical destructions caused by the floods. It is anticipated that the climate change effects through a rise in the sea-level, will aggravate the flooding situation of the town. This paper studies the flood situation of Pekan town, assesses the intensity of flood damages, anticipates the severity of flooding due to sea-level rise and finally, comes up with the community-based sustainable flood mitigation policies and measures for the town
\end{abstract}

Keywords: Climate change; Flood disaster management; Flood damages; nonstructural measures.

eISSN: 2398-4295 @ 2017. The Authors. Published for AMER ABRA by e-International Publishing House, Ltd., UK. This is an open access article under the CC BY-NC-ND license (http://creativecommons.org/licenses/by-ncnd/4.0/). Peer-review under responsibility of AMER (Association of Malaysian Environment-Behaviour Researchers), ABRA (Association of Behavioural Researchers on Asians) and CE-Bs (Centre for EnvironmentBehaviour Studies), Faculty of Architecture, Planning \& Surveying, UniversitiTeknologi MARA, Malaysia.

https://doi.org/10.21834/ajbes.v2i6.33 


\subsection{Introduction}

Floods are the most significant natural disasters which affect 4.9 million people and inflict damages worth of several million every year in Malaysia. About 29,720 square kilometres or $9 \%$ of the land area of the country is prone to flooding (DID, 2007). All the states/ regions of the country experience flooding during the monsoon season. The basic cause of flood in Malaysia is the incidence of heavy monsoon or convective rainfall and the resultant large concentration of runoff which has been exacerbated due to rapid development in the river catchment and deteriorated river capacity $(\mathrm{Ho}, 2002)$. As a result, both the frequency and magnitude of flooding have increased in Malaysia in recent decades. Floods in urban areas bring miseries to the life of thousands of Malaysians every year. With $68 \%$ of the Malaysian population now residing in urban areas, flash flooding in urban areas are perceived to be the most critical flooding type surpassing the monsoon flood since the mid 1990s (DID, 2007). Pekan town is the administrative headquarters of the district located in the state of Pahang, Malaysia. It is situated on the banks of the Pahang River and the town regularly suffers both economic damages and physical destructions caused by the floods. During January 2012, Pekan town and its surrounding areas suffered a flood disaster which affected more than 500 people. However, it is anticipated that the climate change through a rise in the sea-level, will aggravate both the extent, duration and the depth of flooding in the Pekan town. On 05 January, 2013, the Prime Minister of Malaysia has commented that the recent floods in the northern and eastern parts of the country have been aggravated due to the climate change effects. With the above background, this study intends to examine the causes of flooding and its impact on the flood victims in Pekan. It will also propose flood disaster mitigation policies that can help to alleviate the flood vulnerability of Pekan town and its surrounding areas.

\subsection{Objectives}

The aim of this paper is to develop non-structural flood mitigation strategies that are appropriate and sustainable for managing flood disasters in the Pekan town. In order to achieve the above aim, the following objectives have been set for this study:

A. To identify the areas affected with floods in the Pekan town.

B. To analyze the influence of the surrounding land use on flood disasters in the Pekan town.

C. To determine the flood vulnerability of the areas and identify their land use types.

D. To formulate land use policies that can reduce flood disasters in the Pekan town.

\subsection{Literature Review}

Flood disaster management is a multifaceted approach, and it involves several disciplines such as hydrology, water resource management, economics, statistics, population studies, 
public policy and planning. This is due to its impacts it has on the socio-economic livelihood of the people it affects directly and indirectly.

\subsection{Flood Disaster Management - Conceptual and Theoretical Framework}

In order to understand the nature of floods, their causes, impacts and what can be done to reduce the damages caused, the following concepts need elaborations. These are -

Flood - A flood is an overflow of the huge amount of water which submerges land and causes deluge.

Disaster - A disaster is defined as a crisis situation causing widespread damages which far exceed the ability of the residents to recover. Disasters are either natural or man-made.

Flood Plain/ Flood Prone Areas - Floodplain /flood prone area is defined as any land area susceptible to being inundated by water from any source (FEMA, 2007).

Flood Risk and Vulnerable Areas - Identifying hazardous areas and determining risks are the initial steps in the hazard mitigation process. Risks are defined as the type and severity of the hazard and its frequency of occurrence.

Disaster Management - Disaster management (DM) includes the development of disaster recovery plans in order to minimize losses and the implementation of such plans. Disaster management usually refers to the management of natural catastrophes such as fire, flooding, or earthquakes. DM can be undertaken through the following approaches:

Structural Approach - Structural approach is based on the engineering measures adopted to control floods or protect human settlements. They include the building of seawalls and revetments, levees, embankments and others.

Nonstructural Approach - nonstructural approach is based on the adjustments of human activities and societies to mitigate flood damages. It includes insurance, land use management, awareness, environmentally sensitive area protection and other emergency and recovery policies for managing flood damages.

Table 1: Structural and nonstructural flood mitigation measures applied in Malaysia

\begin{tabular}{|ll|}
\hline $\begin{array}{l}\text { STRUCTURAL MEASURES } \\
\text { Include the following: }\end{array}$ & $\begin{array}{l}\text { NON-STRUCTURAL MEASURES } \\
\text { Include the following: }\end{array}$ \\
\hline Flood Control Dams (FCD) & $\begin{array}{l}\text { Integrated River Basin } \\
\text { Management (IRBM) }\end{array}$ \\
& $\begin{array}{l}\text { Preparation of Guidelines and } \\
\text { Canalization and Related Works }\end{array}$ \\
& $\begin{array}{l}\text { Design Standard } \\
\text { Resettlement of Population }\end{array}$ \\
$\begin{array}{l}\text { Poldering (Ring Bund) } \\
\text { Flood Diversion Channel or Tunnel }\end{array}$ & \\
Storage Ponds of Flood Attenuation & Flood Forecasting and Warning \\
& System \\
\hline
\end{tabular}

Source: $h$ ttp://infobanjir.moa.my

Disaster Management Cycle - The actions taken by an organization in response to unexpected events that is adversely affecting people or resources and threatening the continued operation of the organization. It also means measures that are taken to avoid, 
reduce, or eliminate adverse impacts of natural and man-made disasters (Godschalk, 2003; Carter, 1991).

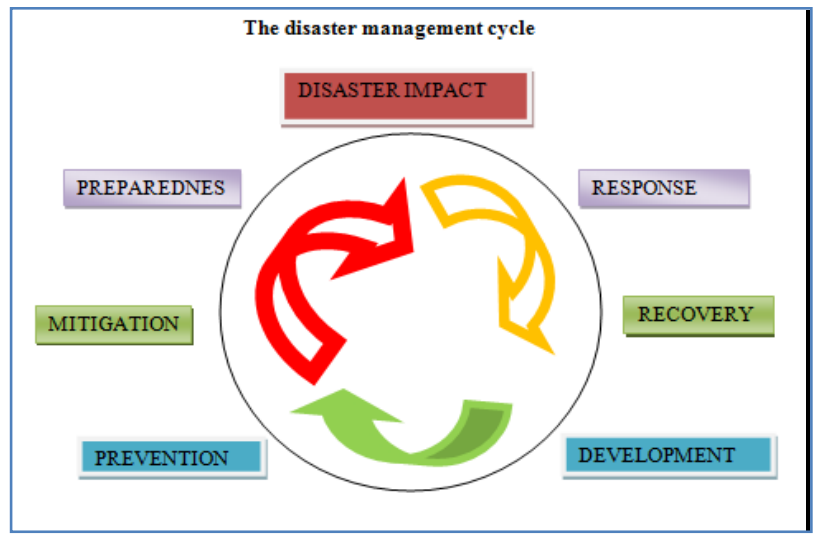

Figure 1: The Disaster Management Cycle

(Source: Carter, 1991)

\subsection{Flood Disaster Studies in Malaysia}

Flood studies in Malaysia are mainly focused on the development of hydraulic models with emphasis mostly on the structural measures. Yan (1987) developed a hydrological model which combined various flood frequency regions and various mean annual flood by regions to estimate design floods for Peninsular Malaysia. A sediment transport equation applicable for rivers in Malaysia was developed by Sinnakaudan et al., (2006) based on sediment data collection carried out from 1994 to 2002 . It was later embedded in a modified version of HEC-6 model and named SEDFlood model by the same authors. A user-friendly menudriven GUI for 2D and 3D digital floodplain delineation was developed based on ArcView GIS and SEDFlood tight coupling procedure. Flood risk maps for the present and future land use can be produced using the SEDFlood model GUI (Sinneakaudan et al., 2006). Billa et al. (undated) developed an integrated MIKE11 hydrodynamic model and ArcView GIS to generate a flood inundation model for early warning in the Langat river basin of Malaysia. Disaster reduction programmes are over-dependent on a reactive approach based largely on technology and not even aimed at floods specifically (Chan, 1997b).

Several studies have been undertaken on social-economic and institutional aspects of floods in Malaysia. Chan (1995) studied the effectiveness of government-run relocation schemes to flood hazards in Malaysia. Liu and Chan (2003) examined the nature and character of flood hazard management programme in Malaysia. In another study, it has been observed that official solutions for flood control are largely engineering based and are ineffective to combat extensive monsoon floods (Chan, 1997a). It has also been observed that current laws and regulations with regard to flood management are also insufficient and 
both the financial and human resources of flood hazard organizations are generally found to be wanting... economic efficiency, equity and public accountability issues are not adequately addressed by institutional arrangements for flood hazards. (Chan, 1997b).

A recent government report, by admitting the shortcomings of the structural approach, has attached significant importance to nonstructural or preventive measures (DID, 2007). Planning and land use policies are basically nonstructural and preventive measures, which can be used to mitigate flood disaster in Peninsular Malaysia. The land use plans, currently in practice in Malaysia, although they consider the drainage issues, lack adequate focus on flooding. Hence, in disaster-prone areas, land use policies can be used to provide direction to development whereby disaster loss of human lives and properties can be minimized. (Mohit \& Karim, 1997). Land use planning policies can also help in achieving sustainable development because they can influence the environment in the following manner: dealing with local site-related matters, ensuring that development does not exceed ecological thresholds, balancing the social, environmental and economic needs of new developments, and maintaining and enhancing the quality of the local environment (Healey and Shaw, 1993; UN, 1977).

\subsection{Methodology}

Methodology in research implies a systematic approach taken to solve a prevailing research issue. A mixed method of quantitative and qualitative approaches was used to achieve the objectives of the research. These included the maps, key informants, GIS data, direct observation, focus group discussion, semi-structured interviews and photographs. In addition, the authors intensively visited the area and talked to local people about their flood miseries and took note of suggestions which they think may be appropriate to combat floods in the area.

\subsection{Study Area}

Located $50 \mathrm{~km}$ south of Kuantan City, on the banks of the Pahang River, Pekan is the royal town of the Malaysian state of Pahang (Fig.2). Pekan is the name of the district in which the town is situated in, and a parliamentary constituency in its own right. It is the home of the state's royal family. It is also the hometown of the second Prime Minister of Malaysia, Tun Abdul Razak Hussein, and the current Prime Minister of Malaysia, Datuk Seri Najib Tun Razak, who is also Pekan's current Member of Parliament.

From the regional perspective, the district is predominantly rural and it has a total population of 103,000 residents (Census 2010). About $86.8 \%$ of the citizens are Malays, $9.9 \%$ Orang Asli, $1.5 \%$ Chinese $0.5 \%$ Indian, and $1.3 \%$ others. The district's economy is dominated by its agriculture, forestry and fishery sectors. Pekan district has the third largest coverage of oil palm plantations and second largest coverage of paddy fields in the State of Pahang. Other economic sectors are construction, transportation services, communication 
and utilities. Despite regular floods, population of the town has increased more than $2.0 \%$ in the recent years. Majority of Pekan residents belong to the low and middle income groups. The surrounding villages rely on Pekan town for the supply of ready-made goods and other services.

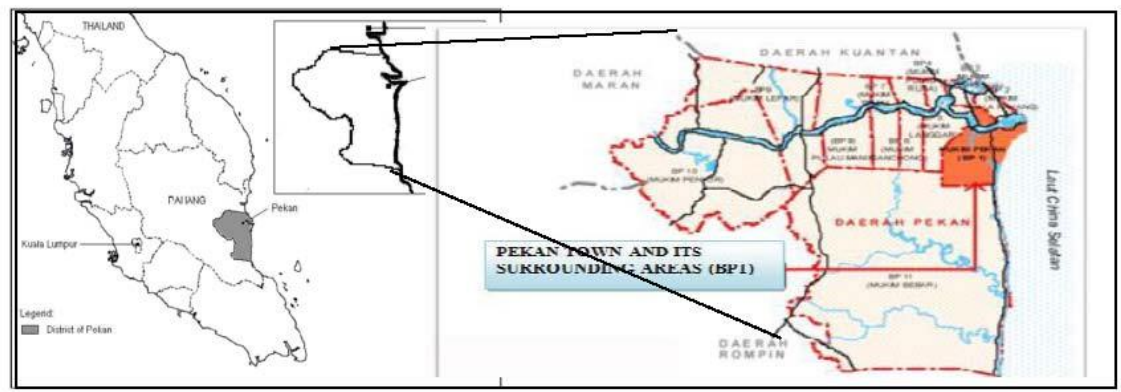

Figure 2: Location of Pekan town and district within regional/ state and national setting.

Pekan has a history of flood. The town being located on the discharge point of the Pahang River is vulnerable to flooding almost every year. The catchment of the river is outside the town, but a major part is within the district where recent development and land use changes have exacerbated the discharge by altering the rainfall-runoff relationship. The annual mean runoff of Pahang River at Lubok Paku point was estimated at $596 \mathrm{~m}^{3} / \mathrm{s}$. In 2007, when the district experienced a two-week duration disastrous flood. There was stagnation in all forms of businesses. Transport and communication was largely disrupted as flood waters reached a height of 2.5 meters along the Pahang River and about 0.5 meter in the town centre on the $14^{\text {th }}$ day of flood water presence (Bernama News, December 2007).

\subsection{Results and Discussions}

Based on the data analysis, the findings of the study have been structured under four headings:

A. Causes of floods in Pekan town and its surrounding areas;

B. Identification of existing flood related issues and problems;

C. The influence of surrounding land uses on the floodability of Pekan town;

D. Flood vulnerability and risk maps;

\subsection{Causes of floods in Pekan town and surrounding areas}

The overflow of the Pahang River during the monsoon season and heavy rainfall are the key factors responsible for floods in Pekan. The intensity of the flood increases when there is high tide in the river. This implies that a rise of the sea level due to climate change will exacerbate both the extent and duration of flood in the district. Coupled with this is the 
topography and geology of the town centre and the district, which are all relatively flat and the soil being soft, can be easily flooded during heavy rains.

\subsection{Identification of flood related issues and problems}

Several flood related issues and problems which contribute to either the miseries of flooding in Pekan, were identified. These are -

\subsection{Incompatible land uses, Poor land use planning, and Lack of zoning}

Residential, commercial, public facilities, infrastructure and the surrounding agricultural activities are not properly zoned. Performance zoning is not in all cases compatible especially when considering the frontage of the Pahang River and the location of residences in the middle of commercial area, lead to land use conflicts.

\subsection{Planning Restrictions}

The height restriction for buildings at a maximum of four floors, because Pekan is a royal town, slows down the development at the town centre. Development is more focused on the adjacent site such as Kampong Peramu which is well known for industrial activities.

\subsection{Improper management of urban activities, poor development guidelines and control}

Effects from earlier development with no upgrading for improvement are evident in Pekan town and its surrounding areas. Some of the sitting arrangements of buildings in the town are not proper. Along Jalan Sultan, we noticed that the road is at a bit higher elevation than the ground floor of the shops. During heavy rains, water enters into the shops and hence remains trapped, and the local residents have to bail out waters.

\subsection{Issues related to flood damages}

A number of issues and problems have been identified related to the role they play in influencing flood damages, and losses in Pekan. These are -
A. Poor drainage systems
B. Narrow drains
C. Low level foundation of houses/structures at the town centre
D. Lack of regular clearance of drains
E. High tides of the Pahang River
F. Siltation and sand mining in the Pahang River

Drains in Pekan town are narrow and shallow and their carrying capacity is low. The excess waters either from heavy rain or overflow of Pahnag River cannot be contained by the shallow drains in the town and its surrounding areas. A local Chinese resident shop owner complained that the poor drainage system contributed to the losses suffered at the town centre during 2007 flood. According to her, the flood waters could not flow and 
increased until the rain seized and it took days for the town to be properly drained. Very few areas in the town had drains that are above 2 feet deep.

Settlements in the town are linearly aligned along the main road which is elevated to be safer from surface waters during normal rains in the town. From interviews with some of the local residents, it was gathered that all the settlements along the river banks are affected during floods.

The Pahang River is very shallow along the town centre. Again, due to siltation from the sand brought in by the Temerloh River, the carrying capacity of the river has been significantly reduced. The river bed is hardly $3 \mathrm{ft}$ deep near the town centre that makes the town susceptible to flooding during high tide and monsoon season. At present, the sand is poorly mined by the local people.

\section{Influence of surrounding land uses on the flooding of Pekan town}

Flood vulnerability of Pekan has also been intensified due to indiscriminate changes of the land uses in the surrounding areas. As the land use changes from agriculture to nonagricultural uses, surface pavement reduces the rain precipitation and rain water runoff increases which lead to flooding of the area. Many residents of Pekan have pointed out to this process of land use changes as contributing to the flooding of the town and district.

\section{Flood Vulnerability and risk map}

Flood Vulnerability according to the UNESCO-IHE institute for water education is the study of flood vulnerability index $(\mathrm{FVI})$ as the extent of harm, which can be expected under certain conditions of exposure, susceptibility and resilience. This is expressed in the following manner:

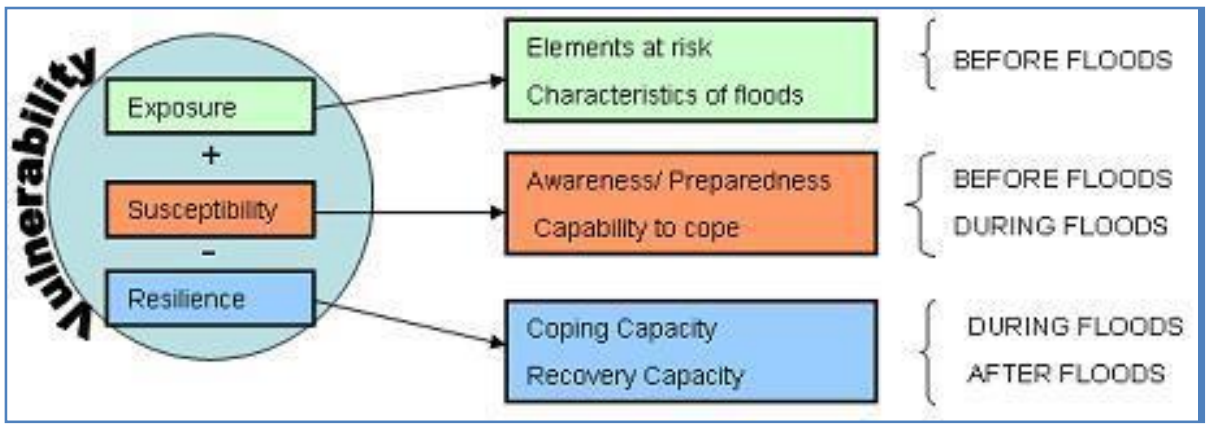

Figure 3: Vulnerability of a system to flood events.

(Source: UNESCO-IHE, in Balicha, 2012)

Exposure is defined as the predisposition of a system to be disrupted by a flooding event due to its location in the same area of influence. Susceptibility relates to system 
characteristics, including the social context of flood damage. It is further defined as the elements exposed within the system, which influence the probabilities of being harms at times of hazardous floods. Resilience is the coping capacity of the community during flood and recovery capacity of the community after flood. The purpose of vulnerability studies is to recognize correct actions that can be taken to reduce the possible effects. To achieve this, local authority with local people and government agencies should be directly involved in a systematic and sustainable manner.

Spatially, it is necessary to convert the flood vulnerability into risk zone maps in order to guide policies and measures. This has been attempted for Pekan town and its adjacent areas (Fig.4). The risk map shows that four communities - Kg Batu Satu Peramu, Kg Pekan river front, Kg Kelapang Tengah and $\mathrm{Kg}$ Pasir, are at high risk zone while $\mathrm{Kg}$ Pulau Jawa and $\mathrm{Kg}$ Alur Akar are at medium risk zone. Pekan town centre and Permatang Pauh are at low risk zone. Table 2 also presents the appropriate development policy measures for each zone.

Table 2. Development policy measures appropriate for each risk zone.

\begin{tabular}{|ll|}
\hline Risk Zones & Development Policy Measures \\
\hline High Risk & Control development, reduce flood risk \\
Medium Risk & Monitor development, reduce flood risk \\
Low Risk & Development should be based on flood sustainability \\
\hline
\end{tabular}

Source: Field Survey, 2012.

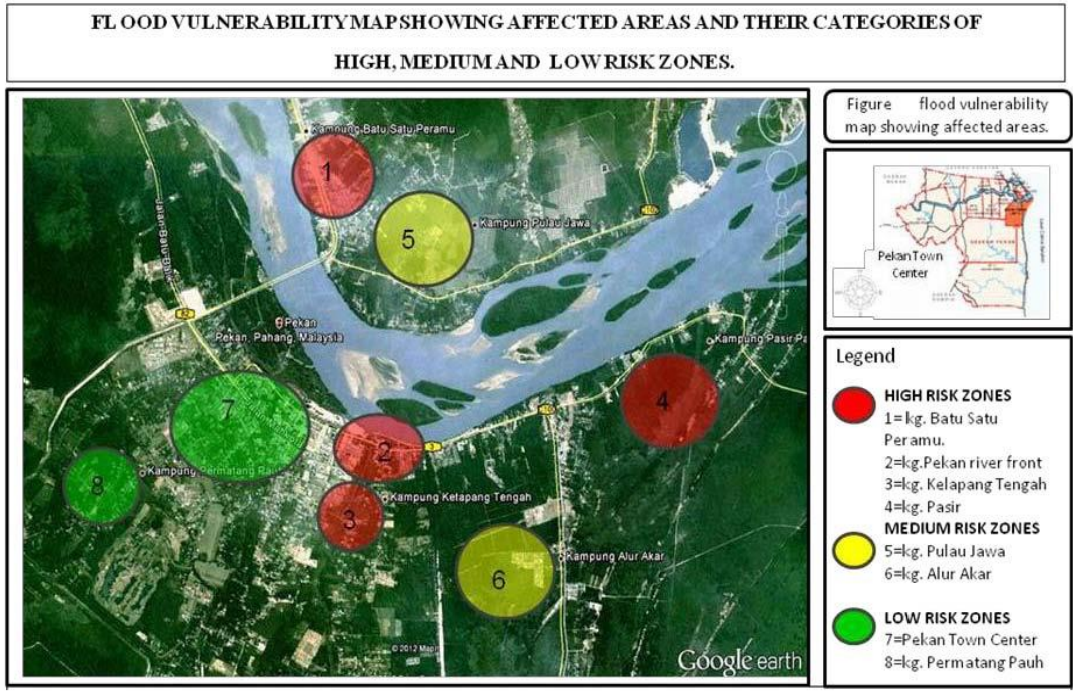

Figure 4: Flood Risk zones of Pekan town and adjacent areas. 


\subsection{Conclusion And Recommendations}

Pekan town and its adjacent areas are vulnerable to flood disaster because of the Pahang River that is flowing through Pekan into the South China Sea. Collective responsibilities through community and agency involvement, have been the strategy used during flood disaster at both response and recovery stages. Further investigation proved that, flood disaster management for Pekan can be promoted through non-structural approach with a greater emphasis on the land use policies and zoning so as to prevent the risk of transforming environmentally sensitive areas prone to floods into agriculture or urban development land uses. Zoning and land use policies are two interrelated mechanisms that will help control, monitor and reduce the risk of flood damages in Pekan town and its adjacent areas. The following recommendations have been formulated towards reducing flood vulnerability of Pekan

\subsection{Short-term measures}

A. Development other than agricultural activities should be discouraged along Pahang River.

B. Forestry, agriculture, tourism and protection of the environment should be prioritised in the land use of the surrounding areas.

C. The river banks with mangrove forest should be zoned as environmentally sensitive areas and conserved.

Local authority should encourage the formation of local sand collectors for planned excavation of sand from Pahang River.

\subsection{Long-term measures}

A. The plinth level of new buildings should be above the current and future flood levels.

B. Keep ground level vacant for parking or other activities in newly constructed public buildings.

C. Control development in high risk areas of Pekan.

D. Widening and regular clearance of drains.

E. Proper use of the new canal.

Finally, the Pekan local plan (2002-2015) has adopted a zonal plan with three categories of broad land uses - potential development areas, potential with condition and preserved areas. The non-structural flood disaster management measures should be incorporated within this framework.

\section{References}

Balicha, S.F. (2012). Applying the flood vulnerability index as a knowledge base for flood risk assessment. Ph.D. thesis. Leiden: CRC/Balkems. 
Bernama News, 14 December 2012.

Billa, L., S. Mansor, A. R. Mahmud and A. H. Ghazali (undated). Integration of RS, GIS and MIKE 11 Hydrodynamic Modeling for Flood Early Warning: A case study of the Langat river basin Malaysia. Malaysia: Spatial \& Numerical Modeling Laboratory Institute of Advanced Technology, UPM.

Canton, L.G. (2007). Emergency Management - Concepts and Strategies for Effective Programs. New Jersey: John Wiley \& Sons Inc. HV551.3C232E.

Carter, W.N. (1991). Disaster management - A Disaster manager's Handbook. Manila: ADB.

Chan, N.W. (1995). "Flood disaster management in Malaysia: an evaluation of the effectiveness of government resettlement schemes". Disaster Prevention and Management Volume 4 Number 41995 pp. 22-29.

Chan, N.W. (1997a). "Increasing flood risk in Malaysia: causes \& solutions", Disaster Prevention and Management: An International Journal, vol.6, no.2, pp.72-86 (15).

Chan, N.W. (1997b). "Institutional Arrangements for Flood Hazards in Malaysia: An Evaluation Using the Criteria Approach", Disaster, vol.21, no.3, pp.406-422.

DID (2007). Flood and Drought Management in Malaysia. Kuala Lumpur: DID.

FEMA (2007). Disaster management. http:// fema.org

Godschalk, D.R. (2003). Urban Hazard Mitigation: Creating Resilient cities, Natural Hazards Review, pp.131-160.

Healey, P. and Shaw T. (1993). "Planners, plans and sustainable development", Regional Studies, vo.27, pp.769776.

Ho, K.H., A.H. Ghazali and Chong, S.F. (2002). "Calibration and Evaluation of Modified Tank Model (Flood Forecasting Model) for Kelantan River Basin". Proceeding of Water Engineering Conference Malaysia, July 23-24, UPM.

Liu, Pin-Shuo, and Ngai Weng Chan (2003). The Malaysian flood hazard management program. International Journal of Emergency Management, vol.1, no.3, pp.205-214.

Mohit, M.A. and A.K.M. Rezaul Karim (1997). "Formulation of Planning and Land Use Policies for Disaster Management in Bangladesh: A Case Study of Chittagong Metropolitan Area", Towards an Improved System for Cyclone Disaster Management in Bangladesh, UNCRD (Japan) Proceeding Series, No. 17, Vol.2, 1997, pp.111-135.

Mohit, M.A. and Sellu, Gajikoh Mohamed (2013). Mitigation of Climate Change Effects through Non-structural Flood Disaster Management in Pekan Town, Malaysia. Procedia - Social and Behavioral Studies, Vol.85, 564-573.

Sinnakaudan, S.K., Aminuddin Ab Ghani, Mohd. Sanusi S. Ahmad and Nor Azazi Zakaria (2003). "Flood risk mapping for Pari River incorporating sediment transport", Environmental Modelling \& Software, vol. 18, issue 2. pp.119-130.

UN (1977). Disaster Prevention and Mitigation - A compendium of Current Knowledge, Vol. 1, (Land Use Aspects). NY: United Nations. 
Mohit, M.A., \& Mohamed Seeu, G. / Asian Journal of Behavioural Studies, AjBeS, Apr / Jun 2017 (p.9-20)

Yan, Ong Chee (1987). Magnitude and Frequency of Floods in Peninsular Malaysia (Revised and Updated). Hydrological Procedure No. 4. KL: DID. 